\title{
Local Control of Acetylcholinesterase Gene Expression in Multinucleated Skeletal Muscle Fibers: Individual Nuclei Respond to Signals from the Overlying Plasma Membrane
}

\author{
Susana G. Rossi, Ana E. Vazquez, and Richard L. Rotundo \\ Department of Cell Biology and Anatomy, University of Miami School of Medicine, Miami, Florida 33136
}

\begin{abstract}
Nuclei in multinucleated skeletal muscle fibers are capable of expressing different sets of muscle-specific genes depending on their locations within the fiber. Here we test the hypothesis that each nucleus can behave autonomously and responds to signals generated locally on the plasma membrane. We used acetylcholinesterase (AChE) as a marker because its transcripts and protein are concentrated at the neuromuscular and myotendenous junctions. First, we show that tetrodotoxin (TTX) reversibly suppresses accumulation of cell surface AChE clusters, whereas veratridine or scorpion venom $(\mathrm{ScVn})$ increase them. AChE mRNA levels are also regulated by membrane depolarization. We then designed chambered cultures that allow application of sodium channel agonists or antagonists to restricted regions of the myotube surface. When a segment of
\end{abstract}

myotube is exposed to TTX, AChE cluster formation is suppressed only on that region. Conversely, $\mathrm{ScVn}$ increases AChE cluster formation only where in contact with the muscle surface. Likewise, both the synthesis and secretion of AChE are shown to be locally regulated. Moreover, using in situ hybridization, we show that the perinuclear accumulation of AChE transcripts also depends on signals that each nucleus receives locally. Thus AChE can be up- and downregulated in adjacent regions of the same myotubes. These results indicate that individual nuclei are responding to locally generated signals for cues regulating gene expression.

Key words: neuromuscular junction; skeletal muscle; gene regulation; muscle differentiation; membrane depolarization; acetylcholinesterase
Skeletal muscle fibers are large multinucleated cells that arise from the fusion of hundreds or thousands of mononucleated myoblasts and in vertebrates can be several centimeters long. These large cells develop morphologically and physiologically specialized regions such as sites of insertion into tendons and bones, the myotendenous junctions, or points of contact with motoneurons, the neuromuscular junctions (NMJs). Different sets of genes are expressed within the specialized domains and along the length of the fibers. Although functional compartmentalization of skeletal muscle, both in culture and in vivo, has been well established by several laboratories including our own (for review, see Hall and Ralston, 1989; Cartaud and Changeux, 1993; Hall and Sanes, 1993), the mechanisms regulating the expression and repression of the many muscle-specific genes along the length of the muscle fibers are less well understood (Termin and Pette, 1992; Fallon and Hall, 1994; Duclert and Changeux, 1995; Burden and Yarden, 1997; Buonanno and Fields, 1999).

Studies on the localized expression of acetylcholinesterase (AChE) transcripts in multinucleated myotubes showed that, once transcribed, the mRNAs do not diffuse very far in these

Received June 3, 1999; revised Nov. 10, 1999; accepted Nov. 11, 1999.

This research was supported by Grant AG05917 from the National Institute on Aging to R.L.R. A.E.V. was a recipient of a minority postdoctoral fellowship supplement from the National Institute on Aging. We thank Julie Bailey for assistance in preparing the chamber cultures during the course of these experiments. We also thank Dr. Daniel Baden for providing the brevetoxin as part of a pilot project sponsored by the National Institute of Environmental Health Sciences Marine and Freshwater Biomedical Sciences Center at the University of Miami, Grant ES05705.

Correspondence should be addressed to Dr. Richard L. Rotundo, Department of Cell Biology and Anatomy (R-124), University of Miami School of Medicine, 1600 N.W. 10th Avenue, Miami, FL 33136. E-mail: rrotundo@miami.edu.

Dr. Vazquez's present address: Department of Otolaryngology, University of Miami School of Medicine, Miami, FL 33136.

Copyright (C) 2000 Society for Neuroscience $\quad 0270-6474 / 00 / 200919-10 \$ 15.00 / 0$ structurally complex cells (Rotundo, 1990). Studies in adult muscle also showed that AChE mRNA levels are significantly higher at sites of nerve-muscle contact, suggesting increased local transcription (Jasmin et al., 1993; Legay et al., 1995; Michel et al., 1994). Moreover, once locally translated, the AChE protein does not diffuse very far (Rossi and Rotundo, 1992, 1996). We also know that AChE is regulated at least in part by muscle activity, the spontaneous or nerve-evoked depolarization of the plasma membrane. Drugs that block membrane depolarization, such as the sodium channel antagonist tetrodotoxin (TTX), inhibit assembly of the collagen-tailed $\left(\mathrm{A}_{12}\right) \mathrm{AChE}$ form that in turn decreases accumulation of AChE on the cell surface (Rieger et al., 1980; Brockman et al., 1984; Fernandez-Valle and Rotundo, 1989). Conversely, sodium channel agonists such as veratridine (Ver) dramatically increase $\mathrm{A}_{12} \mathrm{AChE}$ assembly (De La Porte et al., 1984).

Together, these studies indicate that synthesis, targeting, and localization of $\mathrm{AChE}$ are compartmentalized and suggest that signals generated at the plasma membrane overlying individual nuclei may be responsible for locally regulating AChE expression. To test this hypothesis we developed tissue culture chambers designed to isolate the medium overlying small regions of individual quail myotubes. Sodium channel agonists or antagonists were then added to one side of the chamber, and normal medium or medium with another drug were added to the other side. Thus different regions of the same myotubes were exposed to sometimes opposite acting compounds. Our results show that accumulation of AChE transcripts as well as protein is locally regulated. This local expression suggests that each nucleus must be responding to signals that it receives from the overlying plasma membrane, perhaps through activation of a localized second messen- 
ger system, providing one possible mechanism for the regional differentiation in multinucleated muscle fibers.

\section{MATERIALS AND METHODS}

Preparation of tissue-cultured myotubes and design of chambers. Primary quail myoblasts were cultured in Eagle's Minimal Essential Medium (EMEM) supplemented with $10 \%$ horse serum, $2 \%$ chick embryo extract, and $50 \mu \mathrm{g} / \mathrm{ml}$ gentamycin (normal medium). For conventional cultures, myoblasts were plated on collagen-coated culture dishes and fed on the third and fifth days after plating. To expose different regions of the same muscle fibers to different media, tissue culture chambers were designed based on the Campenot chambers (Campenot, 1987) using 2-cm-diameter plastic or glass rings with a central division made from no. 1 coverslip glass attached using silicone vacuum grease (Corning, Acton, MA) between the side of the division and the ring (see Fig. $1 A, B$ ). The myoblasts were plated on 2.5 -cm-diameter collagen-coated glass coverslips that were lightly scratched with 000 steel wool to promote parallel alignment of the myotubes (Rossi and Rotundo, 1992). The chambers were attached to the coverslips using silicone grease, with the central glass division placed perpendicular to the fibers. When used, pharmacological agents were added to either one or both sides of the chambers from days 4-6 as described under individual experiments. All cell culture supplies were obtained from Life Technologies (Gaithersburg, MD), except horse serum, which was purchased from Gemini BioProducts (Calabasas, CA). Scorpion venom (ScVn) (Androctonus australis), TTX, and Ver were purchased from Sigma (St. Louis, MO).

The following tests were used sequentially to determine the integrity of the sealed partitions. (1) After a partition was placed over the cells, medium was added first to one side of the chamber; if the medium leaked to the other side the culture was discarded. (2) After both sides of the chamber were filled, a drop of trypan blue was added to one side, and the cultures were returned to the incubator; if the dye diffused to the other side, the culture was discarded. (3) The culture chambers that passed the first two tests were then treated experimentally. Before use, myotubes on one side of the chamber were fed with culture medium containing a trace amount of ${ }^{14} \mathrm{C}$-sucrose, and the following day aliquots of medium from each side of the chamber were counted in a liquid scintillation counter. Cultures that did not pass these tests were discarded. Overall, only $10-25 \%$ of the chambers passed the tests.

Assays of cell surface and total and secreted AChE activity: analysis of $A C h E$ forms. Conventional quail muscle cultures were washed three times with $2 \mathrm{ml} \mathrm{HBSS}$, and cell surface AChE activity was assayed by addition of $800 \mu \mathrm{l}$ buffer/substrate solution per dish consisting of $0.6 \mathrm{~mm}$ unlabeled acetylcholine in PBS, $\mathrm{pH} 7.4$, and $0.1 \mu \mathrm{Ci}{ }^{3} \mathrm{H}$-acetylcholine (New England Nuclear, Boston, MA) (specific activity $73.7 \mathrm{mCi} / \mathrm{mmol}$ ) (Rotundo and Fambrough, 1980). This cell surface AChE assay measures only the active enzyme localized on the external surface of the muscle fibers. After a 30 min incubation, $200 \mu \mathrm{l}$ aliquots of the buffer/ substrate solution were removed from each culture dish, and the ${ }^{3} \mathrm{H}$ acetate produced was counted. Cell surface AChE was assayed in the chamber cultures using the same protocol except that the buffer/substrate solution was divided between the two microchambers, and each side was counted separately. In addition, special double chambers were designed to assay cell surface AChE activity. The same myotubes were divided by three glass partitions, the central one as before plus one on each side separated by capillary tubes to form microchambers on each side of the central division. These microchambers were filled with medium plus 5 $\mu \mathrm{M}$ TTX or $20 \mathrm{~nm} \mathrm{ScVn}$ as described in Results.

To measure total AChE activity and to determine the proportions of individual AChE oligomeric forms, conventional cultures were extracted by scraping the cells into $500 \mu \mathrm{l} /$ dish borate extraction buffer $(20 \mathrm{~mm}$ borate buffer, pH 9.0, $1.0 \mathrm{M} \mathrm{NaCl}, 0.5 \%$ Triton X-100, 5 mm EDTA, $0.5 \%$ BSA, $2 \mathrm{~mm}$ benzamidine, $5 \mathrm{~mm} n$-ethyl maleimide, $0.7 \mathrm{~mm}$ bacitracin) as described previously (Rossi and Rotundo, 1992). After centrifugation, the supernatants were either assayed for total AChE activity or the AChE oligomeric forms were determined by velocity sedimentation on 5-20\% sucrose gradients centrifuged for $17 \mathrm{hr}$ at 40,000 rpm in a Beckman SW 41TI rotor. Enzyme activity was assayed using a modification of the radiometric method of Johnson and Russell (1975) as described previously (Rotundo, 1984b).

To determine the relative rates of $\mathrm{AChE}$ secretion, cultures were rinsed three times with HBSS followed by 10 min incubation with $10 \mu \mathrm{M}$ diisopropylfluorophosphate (DFP) in HBSS to irreversibly inhibit all AChE activity. The cultures were rinsed with HBSS to remove unreacted DFP, $350 \mu$ l of modified defined medium (Bottenstein and Sato, 1979) was added to each side of the chambers, and the cultures were returned to the incubator for $7 \mathrm{hr}$. Modified defined medium consisted of EMEM containing $5 \mathrm{mg} / \mathrm{ml} \mathrm{BSA,} 20 \mu \mathrm{g} / \mathrm{ml}$ conalbumin, $5 \mu \mathrm{g} / \mathrm{ml}$ porcine insulin, $50 \mu \mathrm{g} / \mathrm{ml}$ fibronectin, $100 \mu \mathrm{M}$ putrescine, $20 \mathrm{nM}$ progesterone, and $30 \mathrm{nM}$ selenium. At $1 \mathrm{hr}$ intervals, $5 \mu \mathrm{l}$ aliquots of medium were removed from each culture and kept on ice until they were assayed for AChE activity.

Immunofluorescence localization and quantitation of cell surface AChE clusters. Cell surface clusters of AChE were visualized by indirect immunofluorescence (Rossi and Rotundo, 1992, 1993). All incubations were performed in PBS, pH 7.4, containing $10 \%$ horse serum (PBS/HS) using $20 \mu \mathrm{g} / \mathrm{ml}$ of anti-avian AChE mAb 1A2 (Rotundo, 1984a) for 30 min, followed by $10 \mu \mathrm{g} / \mathrm{ml}$ of fluorescein-conjugated rabbit anti-mouse IgG (Cappel, West Chester, PA). The cultures were then fixed with $4 \%$ paraformaldehyde in PBS and incubated with $1 \mu \mathrm{g} / \mathrm{ml}$ Hoechst 33342 in PBS to stain the nuclei. To measure the lengths of differentiated myotubes, fixed cultures were permeabilized with $0.1 \%$ Triton X-100 in PBS, rinsed, and stained with tetramethylrhodamine isothiocyanate (TRITC)phalloidin (Molecular Probes, Eugene, OR) and Hoechst 33342. Chambers were mounted in bicarbonate-buffered $90 \%$ glycerol containing 1 $\mathrm{mg} / \mathrm{ml}$ phenylenediamine and viewed with a $40 \times$ objective on a Zeiss Universal microscope equipped for epifluorescence.

$\mathrm{AChE}$ clusters per nucleus on individual myotubes (conventional cultures) or over the divided fiber (chamber cultures) were quantified as previously described (Rossi and Rotundo, 1992). At least three cultures were analyzed for each experimental group, and 10 randomly selected fields per culture were counted using a $40 \times$ oil immersion objective. The total number of nuclei in myotubes that were counted as well as the total number of AChE clusters associated with those myotubes are indicated for each experiment. Results are expressed as the mean and SE of at least three cultures per group.

Quantitation of AChE $m R N A$ expression by RNase protection assay. Total RNA from muscle cultures grown on $60 \mathrm{~mm}$ culture dishes was isolated after the rapid isolation technique described in Sambrook et al. (1989), with minor modifications of the volumes to allow extraction using $1.5 \mathrm{ml}$ microfuge tubes. A 302 nucleotide fragment of quail AChE cDNA, starting 46 nucleotides upstream from the ATG translation start site, was subcloned in pGEM-4Z in both orientations. The plasmids were linearized with HindIII and used as in vitro transcription templates to produce either antisense ${ }^{32} \mathrm{P}$-labeled probe using $\left(\alpha-{ }^{32} \mathrm{P}\right) \mathrm{UTP}$ (specific activity: $800 \mathrm{Ci} / \mathrm{mmol}$; Dupont NEN, Wilmington, DE) or unlabeled sense transcript for use as a standard. The RNA samples were hybridized overnight at $45^{\circ} \mathrm{C}$ and digested using $6 \mathrm{U}$ RNaseONE (Promega, Madison, WI) per $10 \mu \mathrm{g}$ of RNA for $60 \mathrm{~min}$ at $25^{\circ} \mathrm{C}$ following the manufacturer's recommended protocol. The digests were ethanol-precipitated and electrophoresed on denaturing polyacrylamide urea gels, and the protected RNA was quantitated using a Molecular Dynamics PhosphorImager. The absolute amounts of $\mathrm{AChE} \mathrm{mRNA} \mathrm{protected} \mathrm{were} \mathrm{deter-}$ mined by comparison with known amounts of sense RNA standards assayed in parallel and analyzed using the Image Quant software.

Localization of AChE mRNA by in situ hybridization. Digoxigeninlabeled probes were prepared using the DNA labeling kit from Boehringer Mannheim (Indianapolis, IN) following the manufacturer's recommended protocol. For detection of AChE transcripts, a $2443 \mathrm{bp}$ fragment of quail AChE cDNA, containing $663 \mathrm{bp}$ of $3^{\prime}$ coding region and $1784 \mathrm{bp}$ of $3^{\prime}$ untranslated sequence, served as a template. This probe hybridizes to two bands on Northern blots of total RNA from tissue-cultured quail muscle corresponding to the 5.0 and $5.5 \mathrm{~kb}$ transcripts. The control for background hybridization consisted of digoxigenin-labeled probe prepared from the parental pGEM-4Z plasmid (Promega) linearized using EcoRI.

The in situ hybridization procedure for tissue-cultured myotubes described by Horovitz et al. (1989) was followed with minor modifications. Quail muscle cultures grown on $35 \mathrm{~mm}$ dishes (conventional cultures) or chamber cultures grown on collagen-coated coverslips were fixed for 30 min at $4{ }^{\circ} \mathrm{C}$ with freshly prepared $4 \%$ paraformaldehyde in PBS, pH 7.4. Cultures were washed for $10 \mathrm{~min}$ in PBS and acetylated for $10 \mathrm{~min}$ at room temperature in a solution of $0.15 \mathrm{ml}$ acetic anhydride in $50 \mathrm{ml} 0.1$ $\mathrm{M}$ triethanolamine, $\mathrm{pH} 8$. Cultures were then rinsed three times in $2 \times$ SSC and prehybridized at $55^{\circ} \mathrm{C}$ for $4 \mathrm{hr}$ or overnight in $50 \%$ formamide, $1 \%$ SDS, $10 \mathrm{~mm}$ DTT, $10 \%$ dextran sulfate, $1 \mathrm{~m} \mathrm{NaCl}, 100 \mu \mathrm{g} / \mathrm{ml}$ freshly denatured salmon sperm DNA, and $100 \mu \mathrm{g} / \mathrm{ml}$ yeast RNA. The prehybridization buffer was removed, and a $20 \mu$ l drop of hybridization solution consisting of prehybridization buffer plus $0.1 \mathrm{ng} / \mu \mathrm{l}$ of freshly denatured digoxigenin-labeled DNA probe was placed in the middle of 

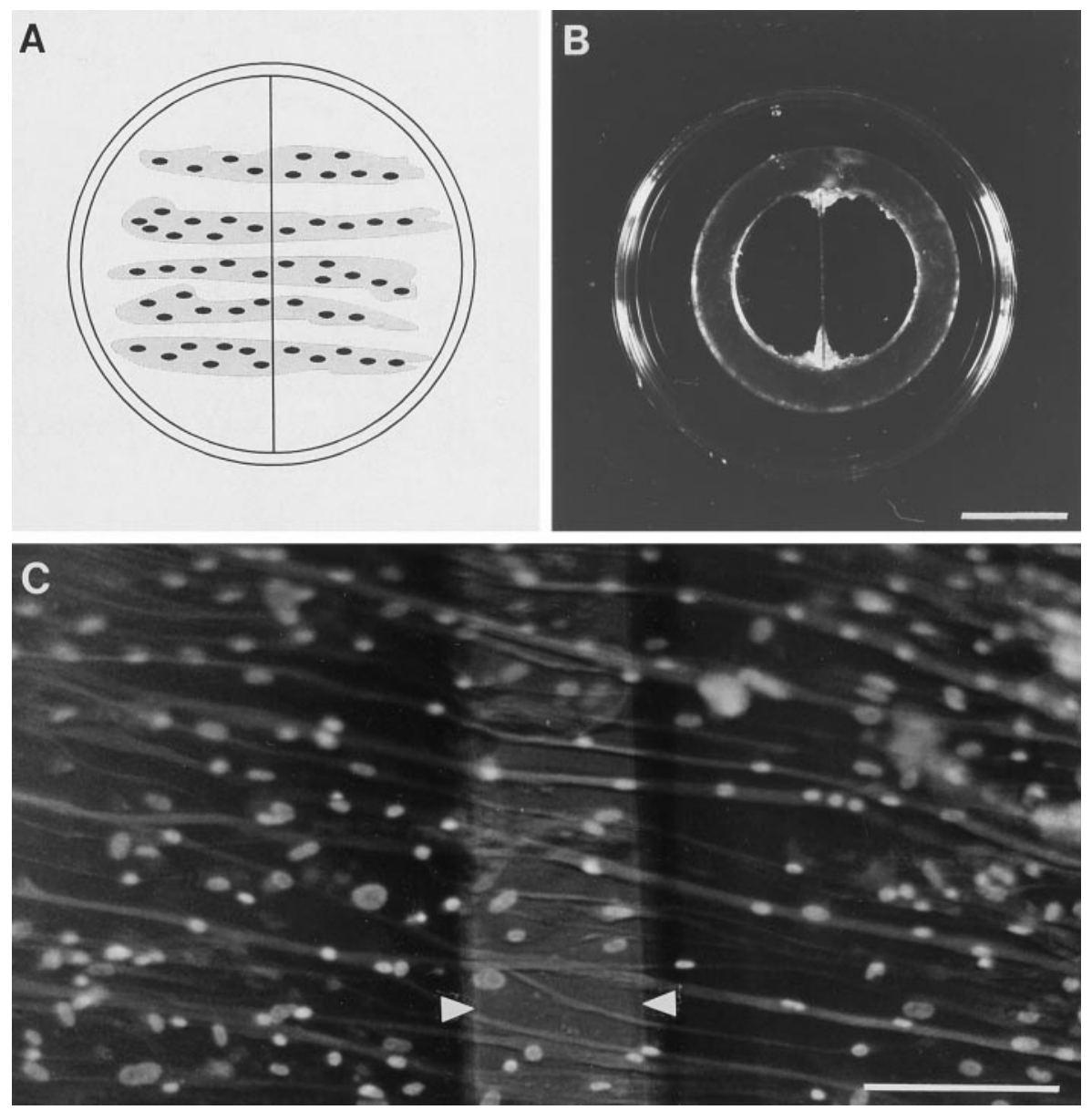

Figure 1. Design of culture chambers to isolate regions of individual myotubes. Myoblasts were plated on scratched collagen-coated glass coverslips and grown in normal medium until they were completely differentiated before the chamber partitions were placed. $A$, Diagram of a culture chamber showing orientation of the myotubes relative to the partition and retaining ring. $B$, Photograph of an actual chamber culture after placement of the partition across the myotubes. Scale bar, $1 \mathrm{~cm}$. The drugs were usually added to one side of the chamber, and the other side served as control. Leakage from one side of the chamber to the other was detected by adding ${ }^{14} \mathrm{C}$-sucrose to one side. $C$, Combined transmitted light/epifluorescence photomicrograph of myotubes stained with Hoechst 33342 to highlight the myonuclei showing that the fibers have grown undisturbed under the glass partition (central part, arrowhead). Scale bar, $100 \mu \mathrm{m}$. the culture, covered with a coverslip, and hybridized overnight at $55^{\circ} \mathrm{C}$. Cultures were then rinsed with $2 \times \mathrm{SSC}$ and washed consecutively at $55^{\circ} \mathrm{C}$ for $30 \mathrm{~min}$ in $50 \%$ formamide with $2 \times$ SSC, $50 \%$ formamide with $1 \times$ $\mathrm{SSC}$, and at room temperature with gentle agitation for $30 \mathrm{~min}$ in $1 \times$ SSC. The hybridized digoxigenin-labeled probe was detected using alkaline phosphatase-conjugated anti-digoxigenin antibody from Boehringer Mannheim at a concentration of $2 \mathrm{U} / \mathrm{ml}$ following the manufacturer's suggested procedure except that incubations with the first antibody were performed for $1 \mathrm{hr}$. Color developing was stopped in all samples at the same time after $12 \mathrm{hr}$, and the cultures were rinsed briefly in PBS. Nuclei were stained using $1 \mu \mathrm{g} / \mathrm{ml}$ Hoechst 33342 in PBS for $20 \mathrm{~min}$. Cultures were washed for $10 \mathrm{~min}$ in PBS and then mounted by placing a $40 \mu \mathrm{l}$ drop of mounting medium $(0.1 \%$ phenylenediamine and $20 \mathrm{~mm}$ bicarbonate buffer, $\mathrm{pH} 9$, in $90 \%$ glycerol) in the middle of the dish and coverslipped.

Quantitation of AChE $m R N A+$ nuclei. Precise quantitation of AChE mRNA was always by RNase protection assay; however, in some experiments we needed to determine the relative distribution of AChE transcripts in different regions of the same fibers. To do this, combined images of Hoechst-stained nuclei and dark-purple precipitate indicative of AChE mRNA in situ hybridization were collected to quantify total number of myotube nuclei and the number of myotube nuclei that had perinuclear in situ hybridization staining. The myotube nuclei that had perinuclear in situ hybridization staining are referred to as AChE mRNA + nuclei throughout this study. Images of seven different fields from each of three dishes per experimental condition were collected in each experiment. The fields were randomly selected from different areas of each dish, making sure the whole dish was sampled. Images were captured using a Princeton Instruments Micro Max camera mounted on a Zeiss Universal microscope equipped for epifluorescence. A combination of epifluorescence and transmitted illumination was used to colocalize nuclei and the in situ alkaline phosphatase staining. The resulting images were analyzed and quantified using Metamorph software (Universal Imaging, West Chester, PA).

\section{RESULTS}

\section{Establishment of parallel myotubes in divided chamber cultures}

Myoblasts plated on lightly scratched collagen-coated glass coverslips continue to proliferate normally with a strong tendency to align with the microscopic grooves in the substratum at the time of fusion. This results in confluent muscle cultures with virtually all of the myotubes lined up in parallel and ensures that approximately equal portions of the fibers will be exposed in each side of the chambers (Fig. 1). When the glass partitions were sealed over the newly formed myotubes on day 4 , the myotubes continued to differentiate, organized a normal myofibrillar apparatus (Fig. 2), and initiated spontaneous contractions around day 5 of culture. The fibers passing under the glass partition exhibited spontaneous contractions on both sides, indicating that the barrier did not disrupt the normal functioning of the cells. The muscle cultures remained healthy for as long as $5 \mathrm{~d}$ after placement of the glass partition, at which time the strong spontaneous contractions usually resulted in detachment of the cells from the coverslips.

The lengths of the myotubes running beneath the partition in the chamber cultures were measured using a calibrated eyepiece micrometer and a $10 \times$ objective. Cultures were fixed, permeabilized with $0.1 \%$ Triton X-100, and incubated with TRITCphalloidin (Molecular Probes) to stain the myofibrillar apparatus and with Hoechst 33342 to label nuclei, facilitating identification and tracing of individual fibers. At least 15 myotubes were measured from each of three cultures. The average length of the 

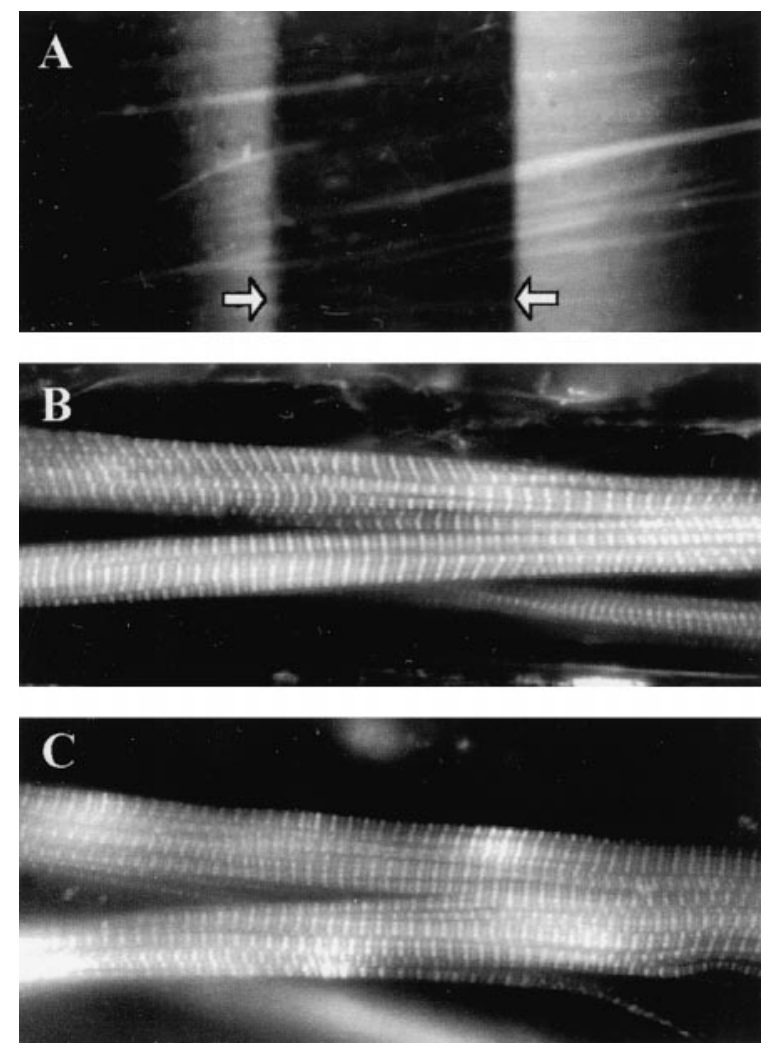

Figure 2. Glass/grease partition does not perturb myotube differentiation. Chambers were placed on top of 4-d-old cultures for $2 \mathrm{~d}$ as detailed in Materials and Methods. Without removing the chambers, cultures were fixed, treated with $0.1 \%$ Triton $\mathrm{X}-100$ for $10 \mathrm{~min}$, and labeled with TRITC-phalloidin for $1 \mathrm{hr}$. Pictures were taken using a $10 \times$ objective $(A)$ to show that the glass partition (between arrows) is located on top of myotubes as in Figure 1. Photomicrographs using a $40 \times$ oil immersion objective $(B, C)$ show details of the myofibrillar apparatus from a region of a myotube located outside the glass partition as a control $(B)$, and from a region of a myotube located under the glass partition $(C)$ showing that the synthesis and assembly of this complex protein structure is unaffected.

myotubes extending beneath the chamber partitions was $1.8 \pm 0.1$ $\mathrm{mm}$. The observation that a normal myofibrillar apparatus develops in the regions of myotube beneath the glass partitions indicates that the chambered cultures do not interfere with the normal metabolic processes of the muscle fibers.

\section{AChE expression is regulated by membrane depolarization}

Studies from several laboratories have shown that synthesis and assembly of AChE are regulated by the activity state of the muscle (Koenig and Vigny, 1978; Brockman et al., 1984; Rubin, 1985; Fernandez-Valle and Rotundo, 1989). For example, sodium channel antagonists such as TTX suppress $\mathrm{A}_{12}$ AChE assembly and cell surface AChE accumulation (Rieger et al., 1980; Koenig et al., 1982; Brockman et al., 1984; Rubin, 1985; Fernandez-Valle and Rotundo, 1989), whereas sodium channel agonists such as Ver increase it (De La Porte et al., 1984; Rubin et al., 1985). Two other sodium channel agonists, ScVn (Sigma) and brevetoxin (BvTx) (kindly provided by Dr. D. Baden), were tested in our experiments with the same results as Ver. In the present studies, we used $\mathrm{ScVn}$ because unlike Ver it is a hydrophilic molecule and acts from the outside of the cells. Veratridine is membrane permeable and therefore its effect is not limited to one side of the chamber.

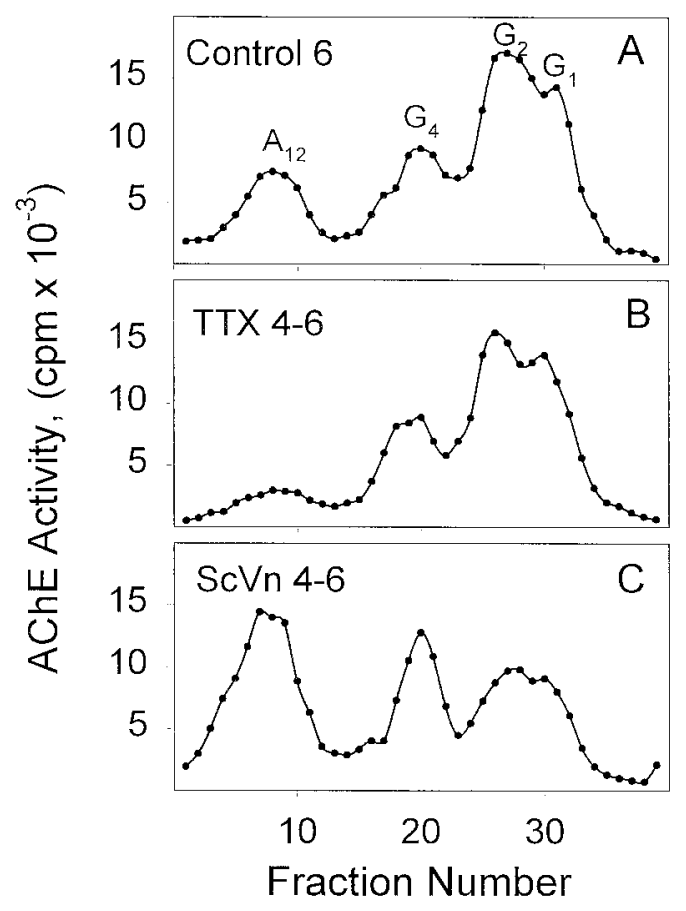

Figure 3. Expression of AChE oligomeric forms in muscle cultures treated with TTX or ScVn. Four-day-old conventional muscle cultures were incubated for $48 \mathrm{hr}$ in either normal medium $(A)$ or medium containing $5 \mu \mathrm{M}$ TTX $(B)$ or $2 \mathrm{~nm} \mathrm{ScVn}(C)$. On day 6, AChE was extracted, and the oligomeric forms were analyzed by velocity sedimentation on sucrose gradients. There is a slight increase in $\mathrm{G} 2 / \mathrm{G} 1$ globular forms in the presence of TTX and a $50 \%$ decrease in the presence of $\mathrm{ScVn}$, suggesting that the newly synthesized enzyme decreases. In contrast, the collagen-tailed $\left(\mathrm{A}_{12}\right)$ AChE form, which predominates in all surface clusters (Rossi and Rotundo, 1992), is decreased by $>50 \%$ in the presence of TTX and doubled in the presence of ScVn, indicating that changes in membrane depolarization mediated by agonists or antagonists of the voltage-dependent sodium channels can regulate AChE expression.

Figure 3 illustrates the effects of TTX and ScVn on the expression of AChE forms. In TTX-treated cultures, the $\mathrm{A}_{12}$ collagentailed $\mathrm{AChE}$ form is reduced to $<25 \%$ of the $\mathrm{A}_{12}$ form in control cultures, whereas there was little or no change in the globular $\mathrm{G}_{2} / \mathrm{G}_{1}$ or $\mathrm{G}_{4}$ forms. In ScVn-treated cultures, the $A_{12}$ form increased to $200 \%$ of controls with a $40 \%$ decrease in the $G_{2} / G_{1}$ and little effect on the $\mathrm{G}_{4}$. Similar results were obtained using Ver and BvTx. The $\mathrm{A}_{12}$ forms in Ver- and BvTx-treated cultures were 264 and $158 \%$, respectively, compared with untreated control cultures. At the same time, $\mathrm{G}_{2} / \mathrm{G}_{1}$ forms in Ver- and BvTx-treated cultures were 46 and $80 \%$ of the $\mathrm{G}_{2} / \mathrm{G}_{1}$ forms in control cultures. Thus the membrane-impermeant sodium channel agonist scorpion toxin is as effective as the more commonly used membranepermeant Ver in increasing expression of $\mathrm{A}_{12}$ AChE while decreasing the levels of the globular $\mathrm{G}_{2} / \mathrm{G}_{1}$ forms.

\section{Local secretion of AChE is regulated by membrane depolarization}

Myotubes normally secrete most of their newly synthesized AChE into the culture medium (Rotundo and Fambrough, 1980), and the relative proportions secreted are influenced in part by membrane depolarization (Fernandez-Valle and Rotundo, 1989). To determine whether local membrane depolarization could regulate the amount of $\mathrm{AChE}$ released into the medium, we measured the rates of AChE secretion in TTX- or ScVn-treated sides of chamber cultures relative to the control side. Enzyme activity 


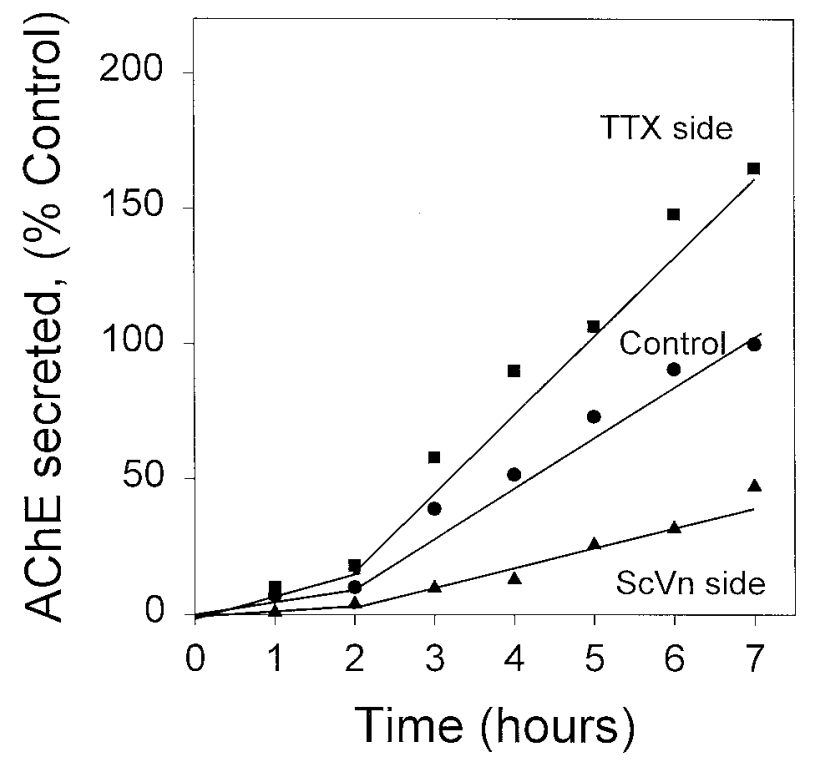

Figure 4. Compartmentalized regulation of $\mathrm{AChE}$ secretion in muscle. Chamber cultures were treated with TTX or ScVn on one side and normal medium on the other from days 4 to 6 . The cultures were then DFPtreated to inhibit all $\mathrm{AChE}$ and returned to the incubator for $7 \mathrm{hr}$ in defined medium with or without sodium channel agonist or antagonist. At hourly intervals, $5 \mu \mathrm{l}$ aliquots of the medium were taken from each side of the chamber to measure newly synthesized secreted AChE activity. Individual values were normalized by expressing them as percentage of the maximum value of the control (untreated) side of each chamber culture. Each plot consists of serial samples from a single culture chamber, and the experiment was repeated twice with identical results.

was measured in aliquots of medium sampled every hour for $7 \mathrm{hr}$, and the resulting activities were plotted as percentage of untreated control side. Figure 4 shows that the rate of $\mathrm{AChE}$ secretion on the TTX-treated side is increased 1.48-fold relative to the control side, whereas the ratio of the $\mathrm{ScVn}$ side to control is 0.24 . Thus, regions of the myotubes exposed to TTX increase their secretion of $\mathrm{AChE}$ into the surrounding medium, whereas secretion by regions exposed to $\mathrm{ScVn}$ is decreased. These results show that the local rate of AChE secretion depends on signals originating on the overlying region of membrane.

\section{Cell surface assay of AChE activity shows local accumulation of the enzyme}

Although most of the newly synthesized AChE in tissue-cultured myotubes is secreted into the medium, a small fraction also becomes attached to the cell surface (Rotundo and Fambrough, 1980). To determine whether local membrane depolarization could regulate the amount of newly synthesized AChE externalized by the myotubes, we measured the relative amounts of enzyme accumulated on the cell surface. Cell surface AChE activity was assayed on myotubes treated from days 4 to 6 with either $5 \mu \mathrm{M}$ TTX or $20 \mathrm{nmM} \mathrm{ScVn}$ as described in Materials and Methods. The results, presented in Table 1, show that cell surface AChE activity in conventional $35 \mathrm{~mm}$ dishes was increased in the presence of $\mathrm{ScVn}$ and decreased in the presence of TTX. Cell surface AChE activity on TTX-treated myotubes was $63 \%$ of $\mathrm{ScVn}$-treated cultures.

Double chambers were then designed to measure cell surface AChE activity on small, 1-mm-wide regions of the myotubes as described in Materials and Methods. TTX was added to one microchamber and $\mathrm{ScVn}$ to the other from days 4 to 6 in culture,
Table 1. Cell surface AChE activity on myotubes is regulated by membrane depolarization

\begin{tabular}{lccllr} 
& \multicolumn{2}{c}{ Conventional cultures } & & \multicolumn{2}{c}{ Double chamber cultures } \\
\cline { 2 - 3 } & $\left(\mathrm{cpm} \times 10^{-3}\right)$ & $\%$ & & Side & $(\mathrm{cpm})$ \\
\hline Control & $9.4 \pm 0.3$ & 100 & & \\
ScVn & $11.4 \pm 0.2$ & 122 & & ScVn & $149 \pm 5$ \\
TTX & $7.2 \pm 0.1$ & 76 & & TTX & $82 \pm 1$ \\
\hline
\end{tabular}

Surface enzyme activity was determined on conventional muscle cultures and on double chamber cultures specially designed to measure cell surface AChE activity after TTX treatment on one side of the microchamber and $\mathrm{ScVn}$ on the other (see Results for details). After exposure to TTX or $\mathrm{ScVn}$ from days 4 to 6 in culture, the double chamber cultures, like the conventional cultures, showed increased cell surface AChE activity on ScVn-treated regions of the myotubes and decreased activity on TTX-treated regions. Thus each region of the myotube surface responds independently to signals originating on its segment of the membrane. Results are expressed as the mean cpm \pm SEM of three cultures per group and as percentage of untreated controls for conventional cultures.

and cell surface AChE activity was measured in each microchamber. Cell surface AChE activity on the TTX-treated side was $82 \pm 1 \mathrm{cpm}$, whereas the ScVn-treated side was $149 \pm 5 \mathrm{cpm}$. Cell surface AChE activity on the TTX-treated region was $55 \%$ of the activity on the $\mathrm{ScVn}$-treated side, measured as an average of three chambers. Thus, like the conventional cultures, cell surface AChE activity assayed in the double chambers showed increased accumulation restricted to regions of the myotubes exposed to $\mathrm{ScVn}$, whereas activity was decreased on regions exposed to TTX. These results (Table 1) indicate that localized opening of the sodium channels results in increased cell surface AChE activity only on the exposed region of the membrane, whereas inhibition of membrane depolarization locally decreases its accumulation.

\section{Regulation of AChE cluster formation by local membrane depolarization}

To determine whether the formation of AChE clusters over individual nuclei could be regulated by locally generated signals, TTX or ScVn was added to one side of the chambers, and normal medium was added to the other from days 4 to 6 in culture. The cultures were then incubated with mAb 1A2 to label cell surface AChE and with Hoechst 33342 to stain the nuclei. Parallel sets of conventional coverslip cultures were treated with TTX or ScVn from days 4 to 6 or fed with normal medium until day 6 (controls). See Figure $5 A-D$ for examples of AChE clusters localized over the nuclei. Quantitation of AChE clusters per nucleus for each group showed that cluster formation was suppressed by TTX and increased by $\mathrm{ScVn}$ only in those fiber regions exposed to the drug, indicating that the accumulation of cell surface AChE over individual nuclei is dependent on the response of the nucleus to signals generated on the overlying plasma membrane. These results are summarized in Table 2.

The number of AChE clusters in treated versus untreated control cultures can also be expressed as a ratio that more clearly compares the results of individual experiments. In the present experiments, the ratio of AChE clusters per nucleus on TTXtreated cultures to clusters per nucleus on control cultures is $0.33 \pm 0.01$. A similar ratio, $0.27 \pm 0.05$, was obtained in chamber cultures, where one side of the chamber was TTX-treated and the other side was kept in normal medium. The ratio of $\mathrm{AChE}$ clusters per nucleus on $\mathrm{ScVn}$-treated versus control cultures was $1.84 \pm 0.40$, whereas a similar value, $1.71 \pm 0.25$, was obtained in chamber cultures where one side of the chamber was treated with 

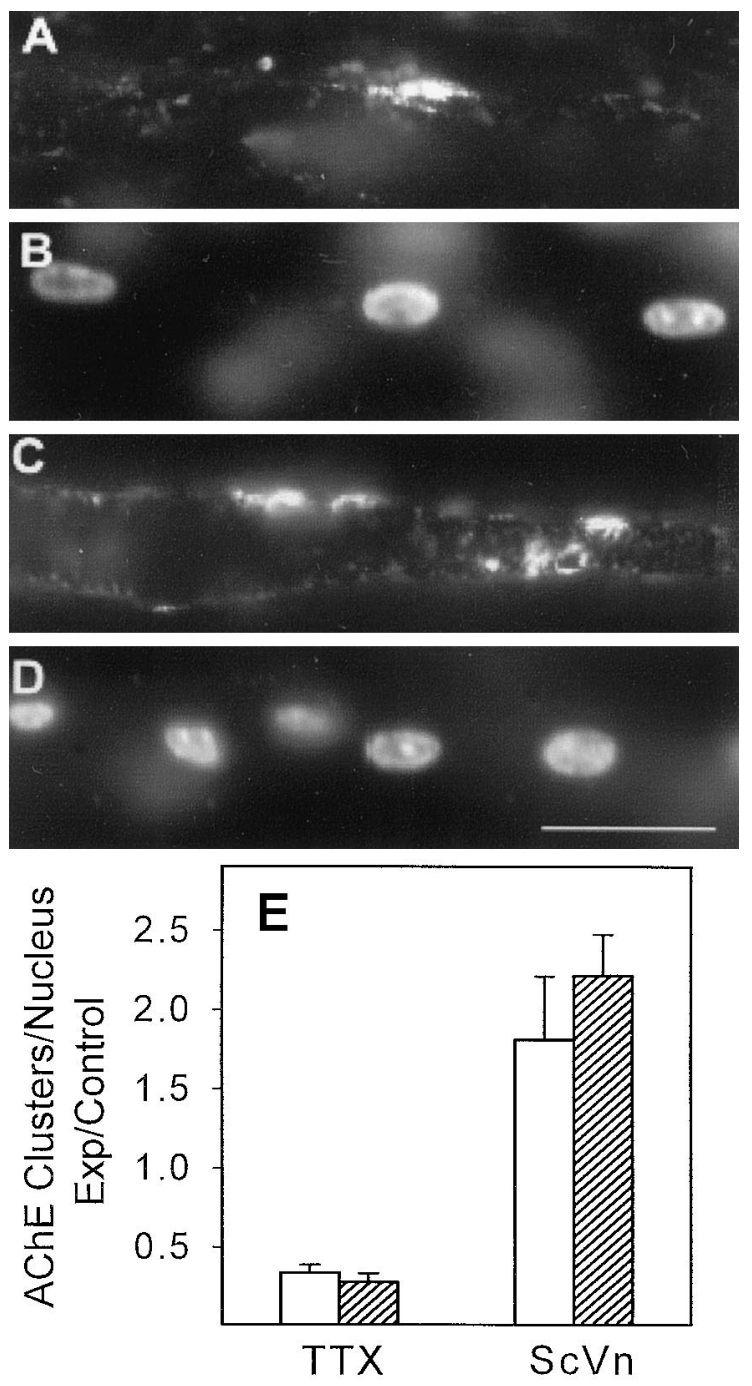

Figure 5. Regulation of cell surface AChE cluster formation on conventional and divided myotubes. Conventional myotube cultures grown on collagen-coated coverslips were incubated in complete medium with or without TTX or ScVn from days 4 to 6 . For divided myotube cultures, TTX or ScVn in complete medium was added to one side of the chamber and complete medium alone to the other side from days 4 to 6 . The cultures were then labeled with mAb $1 \mathrm{~A} 2$ to localize cell surface AChE clusters and Hoechst 33342 to stain the nuclei, and the numbers of nuclei and AChE clusters were quantitated (see Materials and Methods and Table 2). $A, C$, Clusters of AChE visualized by indirect immunofluorescence. $B, D$, Underlying nuclei stained with Hoechst 33342 . $A, B$ and $C, D$ are the same fields viewed through their respective filters. Scale bar, 25 $\mu \mathrm{m}$. $E$, The results of quantitation are expressed as the ratio of AChE clusters per nucleus on the experimental side of the myotubes to the control side. Open bars, Conventional cultures; hatched bars, chamber cultures. Quantitation of AChE clusters per nucleus for each group showed that cluster formation was suppressed by TTX and increased by $\mathrm{ScVn}$ in the conventional cultures and in the chamber cultures only on those fiber regions exposed to the drug, indicating that the clustering of AChE over individual nuclei is dependent on signals generated on the overlying plasma membrane.

$\mathrm{ScVn}$ and the other side kept in normal medium. Figure $5 E$ shows the ratios of $\mathrm{AChE}$ clusters per nucleus on treated cultures versus control on conventional and chamber cultures. Note that the magnitude of the effect is essentially the same using conventional cultures and chamber cultures. These results emphasize the magnitude of the differences between the effects of positive and negative regulators on the accumulation of cell surface AChE and its dependence on local signals.

\section{AChE mRNA levels are regulated by membrane depolarization}

To determine whether AChE transcript levels were regulated by muscle activity, tissue-cultured quail myotubes were treated from day 4 to day 6 with TTX, ScVn, or Ver. Untreated control cultures received normal medium. Total RNA purified from each dish was assayed by RNase protection assay, electrophoresed on denaturing polyacrylamide urea gels, and exposed using a phosphorimager for quantitation by comparison with known $\mathrm{AChE}$ RNA standards (Fig. 6). The values are expressed in terms of percentage of control cells in normal medium $(100 \pm 12 \%)$. AChE mRNA levels are slightly increased in the presence of TTX (126 $\pm 4 \%)$, whereas they are significantly decreased when $\mathrm{ScVn}(15 \pm 7 \%)$ or Ver $(27 \pm 1 \%)$ is added to the medium. Thus the extent and/or frequency of membrane depolarization affects the levels of AChE mRNA in myotubes.

\section{Localization of AChE mRNA in quail muscle cultures}

Preliminary in situ hybridization studies in our laboratory using digoxigenin-labeled cDNA probes for AChE transcripts showed that AChE mRNA is not evenly distributed in the myotubes; rather it is concentrated around individual nuclei (see Fig. 8A,B). This perinuclear localization of AChE mRNA around some but not all of the myonuclei has been described earlier for chicken muscle cultures (Tsim et al., 1992) as well as for human muscle cultures (Grubic et al., 1995). Previous studies from our lab using a quantitative PCR assay in adult avian muscle fibers (Jasmin et al., 1993) as well as studies in adult mammalian muscle (Legay et al., 1995; Michel et al., 1995) have also shown that predominantly specific populations of nuclei, the ones at the neuromuscular junction, express higher levels of AChE transcripts.

To determine whether TTX or ScVn treatments changed the number of nuclei with perinuclear localization of AChE mRNA, quail muscle cultures were analyzed by in situ hybridization after treatment with sodium channel agonists or antagonists from days 4-6. Figure 7 shows in situ hybridization analysis of conventional cultures. The intensity of the perinuclear staining specific for $\mathrm{AChE}$ as well as the extent of the perinuclear area labeled varied considerably depending on the treatment, in agreement with the more quantitative RNase protection studies. Myotubes treated with TTX increased the number of nuclei expressing AChE transcripts, whereas $\mathrm{ScVn}$-treated cells reduced them. The results of quantifying the number of AChE mRNA+ nuclei in these cultures are summarized in Table 3 (see next section for additional discussion).

\section{Compartmentalized regulation of AChE mRNA levels by local membrane depolarization}

The activity state of the muscle clearly affects the levels of AChE transcripts as well as their distribution around the myonuclei. To determine whether AChE mRNA accumulation around individual nuclei was influenced by signals from the overlying region of plasma membrane, culture chambers were treated with TTX or $\mathrm{ScVn}$ on one side of the division and normal medium on the other side from days 4 to 6 . In situ hybridization experiments on chamber cultures followed the same procedure described for conventional cultures. Myotubes that were intact and easily seen to grow under the division of the chamber and extend from the control side to the drug-treated side were identified. The total number of nuclei in each side of each of these fibers was counted, 
Table 2. Quantitation of cell surface AChE clusters on conventional and divided myotube cultures treated with TTX or ScVn

Conventional cultures

\begin{tabular}{|c|c|c|c|c|c|c|c|}
\hline Treatment & $\begin{array}{l}\text { Total } \\
\text { nuclei }\end{array}$ & $\begin{array}{l}\text { Total } \\
\text { clusters }\end{array}$ & $\begin{array}{l}\text { Clusters/ } \\
\text { nucleus }\end{array}$ & $\begin{array}{l}\text { Treatment } \\
\text { (side) }\end{array}$ & $\begin{array}{l}\text { Total } \\
\text { nuclei }\end{array}$ & $\begin{array}{l}\text { Total } \\
\text { clusters }\end{array}$ & $\begin{array}{l}\text { Clusters/ } \\
\text { nucleus }\end{array}$ \\
\hline TTX & 808 & 61 & $0.11 \pm 0.04$ & TTX & 211 & 24 & $0.13 \pm 0.03$ \\
\hline Control & 861 & 175 & $0.33 \pm 0.03$ & Control & 220 & 97 & $0.49 \pm 0.05$ \\
\hline $\mathrm{ScVn}$ & 211 & 113 & $0.46 \pm 0.10$ & $\mathrm{ScVn}$ & 217 & 135 & $0.58 \pm 0.08$ \\
\hline Control & 375 & 97 & $0.25 \pm 0.01$ & Control & 128 & 44 & $0.34 \pm 0.09$ \\
\hline
\end{tabular}

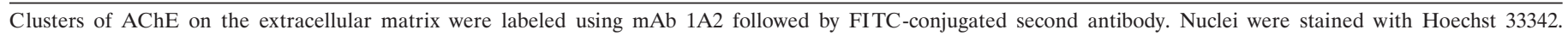

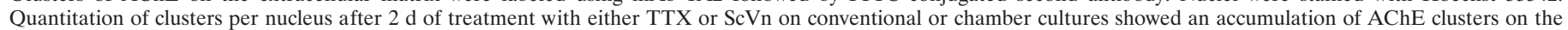

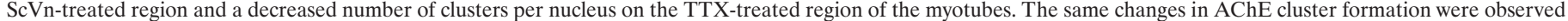

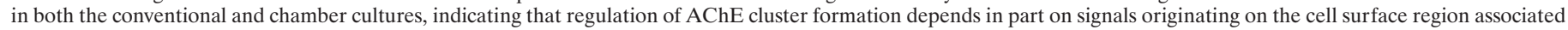
with the cluster.

A

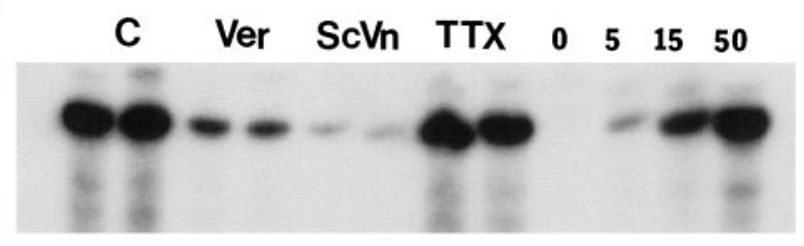

B

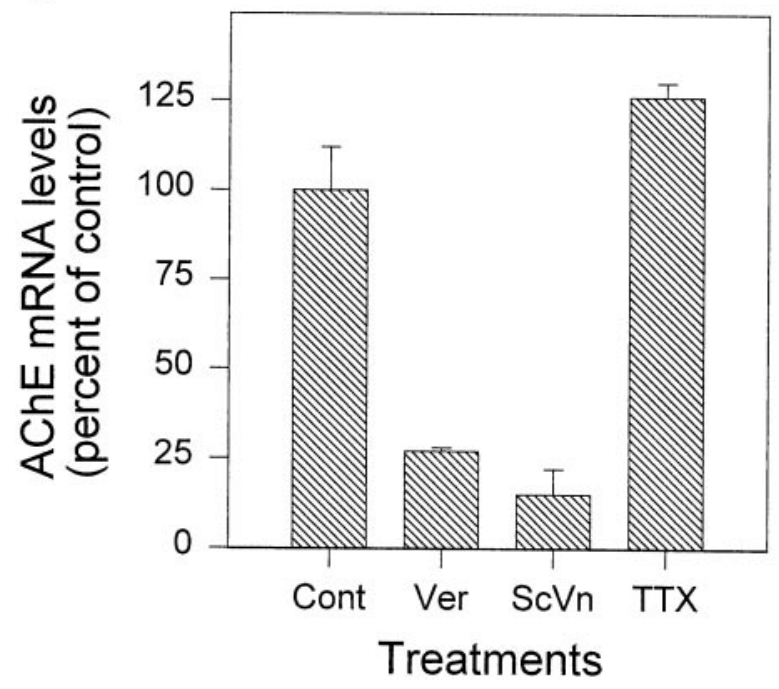

Figure 6. Regulation of AChE mRNA levels by membrane depolarization. Conventional quail muscle cultures were incubated from days 4 to 6 in complete medium with or without TTX, ScVn, or Ver, and the AChE transcript levels were measured by RNase protection assay (for details, see Materials and Methods). A, Autoradiogram of PAGE analysis of protected AChE mRNA isolated from control cultures $(C)$ or cultures treated with Ver, $\mathrm{ScVn}$, or TTX. The last four lanes are the protected bands from $10 \mu \mathrm{g}$ of yeast RNA containing $0,5,15$, and $50 \mathrm{pg}$ of an in vitro-transcribed synthetic sense AChE transcript used as a standard. $B$, Quantitation of AChE mRNA levels, expressed as percentage of untreated control cultures. Treatment of cultures with TTX resulted in slightly increased AChE mRNA levels, whereas treatment with Ver or $\mathrm{ScVn}$ reduced the transcript levels by $75-90 \%$.

and the number of nuclei that had AChE mRNA accumulations (AChE mRNA+ nuclei) was determined for each side of the same fibers. In this way, the percentage of AChE mRNA+ nuclei could be calculated for each side of the chambers. For the TTXtreated group, $37 \%$ of the nuclei in the control side of the chambers were AChE mRNA+, whereas in the TTX-treated side
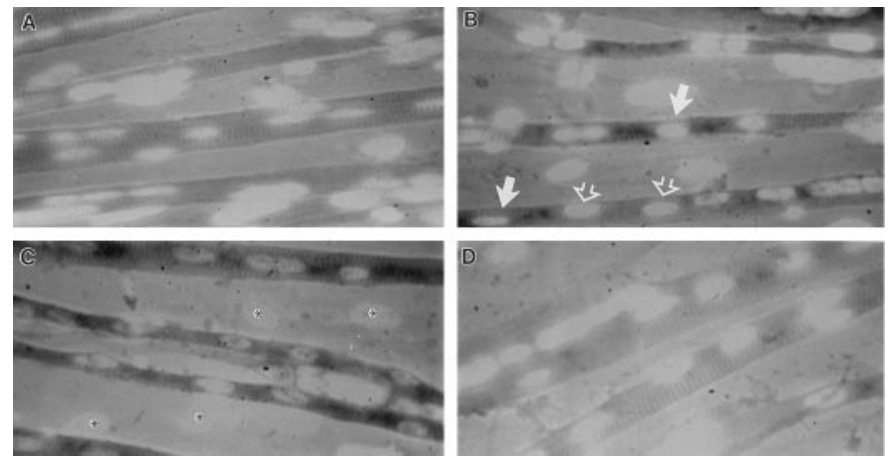

Figure 7. Membrane depolarization reduces the number of AChE mRNA-positive nuclei in tissue-cultured myotubes. Quail muscle cultures were incubated from days 4 to 6 in the presence or absence of TTX or $\mathrm{ScVn}$ and analyzed by in situ hybridization using a digoxigenin-labeled random-primed quail AChE cDNA probe. After development of the reaction product (dark staining), the nuclei were stained with Hoescht 33342 , and the photomicrographs were taken with a combination of transmitted and fluorescence illumination to show the close relationship of the in situ hybridization product to the myonuclei. $A$, Background control using plasmid vector pGEM-4Z DNA probe alone; $B$, distribution of AChE transcripts in untreated control cultures; $C$, distribution of AChE transcripts in cultures treated with TTX from days 4 to $6 ; D$, distribution of AChE transcripts in cultures treated with $\mathrm{ScVn}$. Treatment of myotubes with TTX, a sodium channel blocker, increased the number of nuclei expressing $\mathrm{AChE}$ transcripts, whereas treatment with $\mathrm{ScVn}$, a sodium channel agonist, reduced the number of nuclei expressing AChE transcripts. Solid arrows, Nuclei with AChE mRNA reaction product counted as positive; open arrows, nuclei counted as negative (see Fig. 8 for a higher power photomicrograph). The large nuclei of the fibroblasts, marked with asterisks in $C$, are always negative compared with the smaller myonuclei in myotubes. Note that the fibroblasts occupy much of the space between the multinucleated myotubes characterized by their small oval nuclei.

$60 \%$ of the nuclei were AChE mRNA+. For the ScVn-treated group, $31 \%$ of the nuclei in the control side were AChE mRNA+, whereas in the $\mathrm{ScVn}$-treated side the percentage was much lower: only $14 \%$ of the nuclei were AChE mRNA+. In a separate series of experiments, conventional cultures were treated with TTX or $\mathrm{ScVn}$ from days 4 to 6 or kept in normal medium as controls. After in situ hybridization and staining of nuclei, the total and AChE mRNA + nuclei in seven fields of each of three independent dishes in two separate experiments were counted, and the percentage of AChE mRNA+ nuclei was then calculated. Results from the conventional cultures were essentially the same as results obtained with the chamber cultures. In the control conventional cultures, 24 and $33 \%$ (experiments 1 and 2, respectively) of the nuclei were AChE mRNA+. When treated with TTX, the per- 
Table 3. Quantitation of AChE mRNA+ nuclei in conventional and divided myotube cultures treated with TTX or ScVn

Conventional cultures

\begin{tabular}{|c|c|c|c|c|c|c|c|}
\hline Treatment & $\begin{array}{l}\text { Total number } \\
\text { of nuclei }^{a}\end{array}$ & $\begin{array}{l}\text { AChE } \\
\text { mRNA+ nuclei }\end{array}$ & $\begin{array}{l}\text { AChE mRNA+ nuclei } \\
(\% \text { of total })\end{array}$ & Treatment & $\begin{array}{l}\text { Total number } \\
\text { of nuclei }{ }^{b}\end{array}$ & $\begin{array}{l}\text { AChE } \\
\text { mRNA+ nuclei }\end{array}$ & $\begin{array}{l}\text { AChE mRNA+ nuclei } \\
\text { (\% of total) }\end{array}$ \\
\hline \multicolumn{8}{|l|}{ Control } \\
\hline Experiment 1 & 721 & 178 & $25 \pm 5$ & & & & \\
\hline Experiment 2 & 501 & 164 & $33 \pm 2$ & & & & \\
\hline \multicolumn{8}{|l|}{$\mathrm{ScVn}$} \\
\hline Experiment 1 & 641 & 105 & $16 \pm 4$ & Control side & 94 & 29 & $31 \pm 8$ \\
\hline Experiment 2 & 506 & 75 & $15 \pm 4$ & ScVn side & 135 & 19 & $14 \pm 7$ \\
\hline \multicolumn{8}{|l|}{ TTX } \\
\hline Experiment 1 & 771 & 471 & $61 \pm 3$ & Control side & 65 & 24 & $37 \pm 9$ \\
\hline Experiment 2 & 457 & 302 & $66 \pm 3$ & TTX side & 71 & 43 & $60 \pm 8$ \\
\hline
\end{tabular}

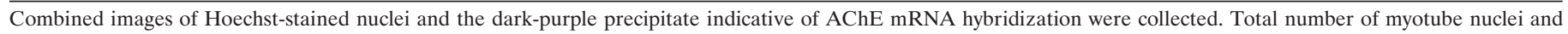

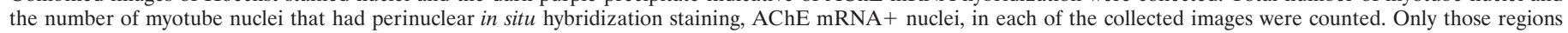

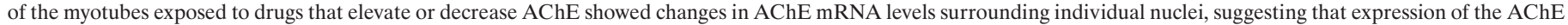
gene is locally controlled.

${ }^{a}$ For each experiment, nuclei in seven randomly selected fields in each of three culture dishes per group were counted.

${ }^{b}$ For each chamber, nuclei in at least five myotubes were counted.

centage of AChE mRNA+ nuclei increased to 61 and $66 \%$, respectively, whereas $\mathrm{ScVn}$ treatment decreased the percentage of AChE mRNA+ nuclei to 16 and $15 \%$. The total number of nuclei counted in each experiment and results are summarized in Table 3. Expressing the numbers of RNA+ nuclei as percentage of untreated controls (Fig. $8 C$ ) allows a better comparison of the conventional and chambered cultures and clearly shows the localized suppressive effects of membrane depolarization on $\mathrm{AChE}$ mRNA expression.

\section{DISCUSSION}

Studies from several laboratories, including our own, have established that skeletal muscle fibers are highly compartmentalized with respect to the expression of several muscle-specific proteins and genes (for review, see Hall and Ralston, 1989; Cartaud and Changeux, 1993; Duclert and Changeux, 1995). Thus sarcoplasmic proteins synthesized in the vicinity of one myonucleus have a low probability, on average, of diff using to the vicinity of another nucleus. Likewise, transcripts expressed by one nucleus have a low probability of translation on the endoplasmic reticulum in the vicinity of another nucleus. Although the mechanisms underlying this compartmentalization are not known, it is likely that simple physical barriers, such as limits in the volume of cytoplasm surrounding a given nucleus and restrictions in space occupied by the dense myofibrillar apparatus, play as much a role as more highly organized mechanisms such as interactions of specific transcripts with cytoskeletal elements and localized second messenger systems. Clearly one initial step in establishing these compartments must involve the establishment of local patterns of gene expression.

One possible mechanism for establishing unique patterns of gene expression in different regions of multinucleated skeletal muscle fibers could depend on the timing of cell fusion or origin of myoblasts, giving rise to the myonuclei of the different regions of the fiber. During skeletal muscle development, nuclei contributed by the earliest myoblasts to fuse tend to be localized in the central region of the fibers, whereas nuclei located in the region of the myotendenous junctions tend to derive from later populations of myoblasts. This is because myoblasts tend to fuse at the ends of the fibers, and therefore the fibers grow in length by addition to the myotendenous region. This model would suggest that differ- ent populations of myoblasts were committed to different patterns of gene expression, with the earlier progenitors giving rise to the subsynaptic nuclei and later ones giving rise to those in the extrajunctional regions and later those of the myotendenous junction.

Another possibility is that the myoblasts fusing with a given muscle fiber are essentially identical with respect to their repertoire of expressed genes and that this repertoire becomes more highly specified depending on where in the fibers the nuclei reside. In this model each nucleus would receive information generated locally and would alter its expression of specific genes accordingly. Although the muscle phenotype is specified during determination of the myogenic lineage (Cossu et al., 1996; Molkentin and Olson, 1996), this local control of gene expression would constitute more of a fine tuning of the phenotype, a highly refined mechanism for mediating plasticity in accord with the physiological demands imposed on the muscle. At the same time, this type of mechanism would also facilitate repair of damaged muscle by allowing local fusion of satellite cells wherever needed that in turn would express whichever proteins were locally required, like the induction of new NMJ-like domains in muscle in vivo by local expression of the MuSK kinase domain (Jones et al., 1999).

Acetylcholinesterase is an excellent marker for studying local regulation of gene expression because it is regulated at least in part by muscle activity, and in adult muscle it is restricted to specific regions of the fibers such as the neuromuscular and myotendenous junctions. In noninnervated regions of the fibers, referred to as extrajunctional, expression of AChE is usually suppressed (for review, see Massoulié et al., 1993). At the vertebrate neuromuscular junction, for example, AChE protein and transcripts are more highly expressed than in the neighboring extrajunctional segments (Jasmin et al., 1993; Legay et al., 1995; Michel et al., 1994), and in fact the levels drop dramatically outside the 50 - to $100-\mu \mathrm{m}$-wide region of innervation. Thus compartmental boundaries are narrowly defined in vivo and may reflect the same underlying mechanisms found in cultured muscle cells. However, the cellular signals as well as the molecular mechanisms responsible for the downregulation of $\mathrm{AChE}$ in 

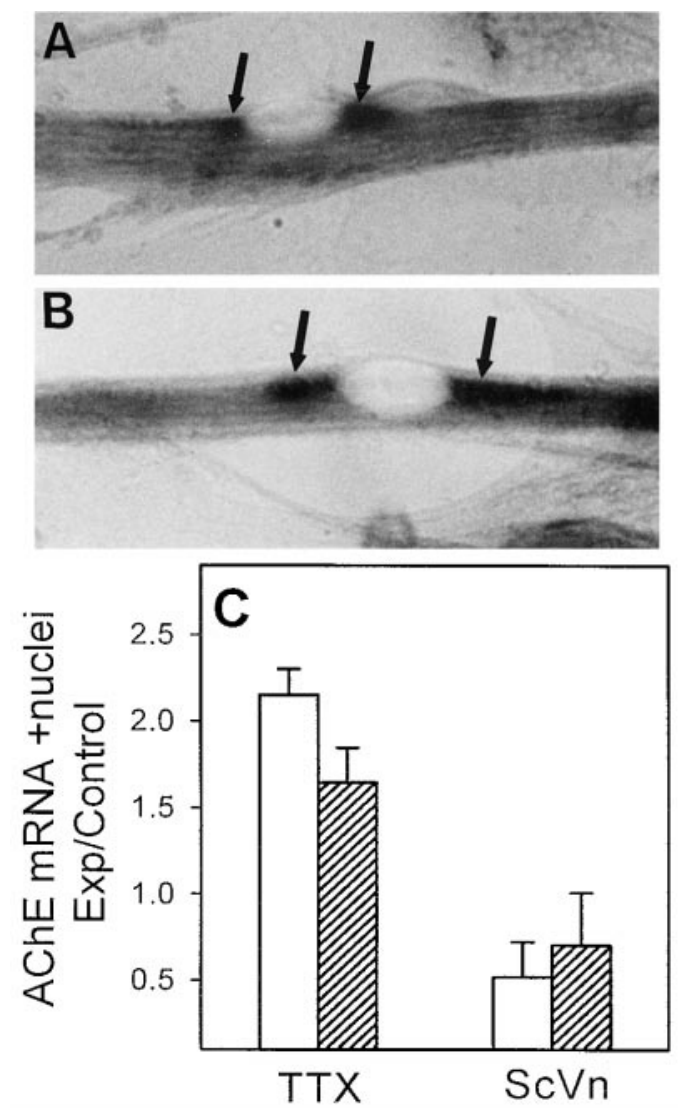

Figure 8. Local control of AChE mRNA expression in myonuclei underlying regions of plasma membrane exposed to sodium channel agonists or antagonists. Chamber cultures were prepared as described in Materials and Methods, and either TTX or ScVn was added to one side of the chambers from days 4 to 6 . Conventional cultures were treated in parallel. $A, B$, Enlarged segment of two myotubes showing perinuclear distribution of the AChE mRNA in situ hybridization reaction product. The cells were stained as described in the legend to Figure 7. $C$, The ratio of AChE mRNA+ nuclei to the total number of nuclei in divided myotubes was determined by in situ hybridization (hatched bars). Just as for conventional cultures (open bars), treatment with a sodium channel blocker increases the number of nuclei expressing AChE transcripts, whereas treatment with sodium channel agonist reduced the number of nuclei expressing AChE mRNA. These effects are restricted to nuclei underlying regions of the plasma membrane exposed to the drugs, indicating that each nucleus responds to locally generated signals originating at the overlying plasma membrane.

noninnervated regions of the fibers, and the upregulation of the enzyme at the neuromuscular junction, are still unknown.

To study the compartmentalized regulation of AChE, we adapted the partitioned culture chambers developed by Campenot (1987) to muscle fibers by first growing the myotubes on scratched collagen-coated coverslips, which promotes parallel fiber growth, followed by placement of a glass partition sealed with silicone grease perpendicular to the myotubes (Fig. 1). A successful seal is totally dependent on an even coating of silicone grease on the bottom of the glass partition and occurs approximately 1 out every 5-10 tries. Once in place, however, the partition does not perturb the cells and differentiation proceeds normally (Fig. 2).

Regulation of AChE occurs at several levels in electrically excitable cells. In the present studies we have shown that at least four separate levels of $\mathrm{AChE}$ regulation are controlled at the local level in multinucleated muscle fibers (Table 4). Secretion is the fate of the majority of newly synthesized AChE molecules in
Table 4. Summary of effects of scorpion venom and tetrodotoxin on $\mathrm{AChE}$

\begin{tabular}{lll} 
& Treatment & \\
\cline { 2 - 3 } & Scorpion venom & Tetrodotoxin \\
\hline AChE synthesis & $\downarrow$ & - \\
AChE secretion & $\downarrow$ & $\uparrow$ \\
Cell surface AChE activity & $\uparrow$ & $\downarrow$ \\
Cell surface clusters/nucleus & $\uparrow$ & $\downarrow$ \\
Total AChE mRNA & $\downarrow$ & $\uparrow$ \\
AChE mRNA positive nuclei & $\downarrow$ & $\uparrow$
\end{tabular}

Various parameters of AChE biogenesis and regulation are shown and whether the effects of the drugs act to increase $(\uparrow)$ or decrease $(\downarrow)$ it, or $(-)$ no change.

tissue-cultured muscle (Rotundo and Fambrough, 1980), and therefore the rate of secretion closely parallels the rate of synthesis. The observation that secretion of $\mathrm{AChE}$ is increased in regions of the myotubes exposed to TTX and reduced in regions treated with $\mathrm{ScVn}$ implies that the synthesis of the enzyme is regulated by local membrane activity (Fig. 4). At the same time, the levels of AChE transcripts are regulated in parallel. Blocking membrane depolarization with TTX results in increased levels of AChE transcripts, whereas chronic membrane depolarization using $\mathrm{ScVn}$ results in decreased AChE mRNA only around those nuclei located in the treated region (Figs. 7, 8; Table 3). A similar parallel regulation of nicotinic ACh receptor subunit proteins and transcripts is well established in both birds and mammals (for review, see Hall and Sanes, 1993; Duclert and Changeux, 1995).

It is of interest to note the distribution of AChE mRNA in the myotubes (Fig. 7). In most myotubes the AChE transcripts appear as bilateral accumulations at the poles of the oval-shaped myonuclei, which are clearly visible in untreated myotubes. When AChE mRNA levels are upregulated, as when the cells are treated with TTX, the transcripts appear to fill the myotubes (Fig. $7 C$ ), whereas when the transcripts are downregulated with $\mathrm{ScVn}$, only a few nuclei present local accumulations of AChE mRNA (Fig. 7D). Changes in AChE mRNA levels are reflected not only in changes in the absolute levels of transcripts measured using a sensitive RNase protection assay (Fig. 6), they are also reflected in changes in the numbers of nuclei that exhibit perinuclear accumulations of AChE mRNA (Fig. 8C). These observations suggest that regulation of the AChE transcript could be an "on/off" event at individual nuclei within the myotubes. This intriguing possibility remains to be tested directly.

After synthesis on the rough endoplasmic reticulum and assembly into the globular dimeric and tetrameric AChE forms, a subset of the catalytic subunits also is assembled with the noncatalytic collagen-like tail (Rotundo, 1984a). The collagen-like tail is necessary for attachment of $\mathrm{AChE}$ to the extracellular matrix of muscle and the formation of cell surface clusters of the enzyme (Rotundo et al., 1997; Peng et al., 1999). The assembly of AChE catalytic subunits with the collagen-like tail also depends on membrane depolarization. In denervated muscle, or muscle paralyzed by TTX, the collagen-tailed form is not assembled (for review, see Massoulié et al., 1993). In tissue-cultured muscle, the assembly of the collagen-tailed form is inhibited in the presence of TTX and enhanced in the presence of Na channel agonists such as Ver or ScVn [De La Porte et al. (1984), and Fig. 3]. In the chamber cultures, TTX blocks the accumulation of cell surface $\mathrm{AChE}$, whereas $\mathrm{ScVn}$ increases it (Table 1). As would be predicted by the lack of assembly of the collagen-tailed AChE, TTX 
also blocks the formation of cell surface AChE clusters (Fig. $5 E$, Table 2), and in parallel with the increase of cell surface AChE after treatment with $\mathrm{ScVn}$, there is also an increase in the formation of AChE clusters. That these changes also occur over the small regions of the surface of the myotubes that are exposed to the drugs in the chambered cultures indicates that the area around each nucleus is responding autonomously to the locally generated signals. The formation of AChE clusters is especially important because these clusters also include several other molecular components of the neuromuscular junction, including the nicotinic acetylcholine receptor and heparan sulfate proteoglycan (perlecan).

We have shown that the expression of AChE can be locally controlled in multinucleated skeletal muscle fibers at the levels of mRNA accumulation, protein synthesis, assembly, secretion, accumulation on the cell surface, and finally in the formation of clusters with other synaptic components. In each case the signals that regulate the specific molecular processes can be shown to originate on the plasma membrane, because in each case local changes in membrane depolarization are what gave rise to the observed changes. The changes in membrane depolarization that decrease AChE transcript levels and increase assembly of the collagen-tailed form of the enzyme are similar to those that occur during normal physiological activity in the mature fibers, as well as during spontaneous contraction of muscle that occurs after onset of differentiation in culture. Thus it is likely that similar mechanisms operate to downregulate AChE expression in extrajunctional regions of muscle and increase expression of the matrix-bound form of the enzyme in junctional regions of the fibers.

\section{REFERENCES}

Bottenstein JE, Sato GH (1979) Growth of a rat neuroblastoma cell line in serum-free supplemented medium. Proc Natl Acad Sci USA 76:514-517.

Brockman SK, Younkin LH, Younkin SG (1984) The effect of spontaneous electromechanical activity on the metabolism of acetylcholinesterase in cultured embryonic rat myotubes. J Neurosci 4:131-140.

Buonanno A, Fields RD (1999) Gene regulation by patterned electrical activity during neural and skeletal muscle development. Curr Opin Neurobiol 9:110-120.

Burden S, Yarden Y (1997) Neurogulins and their receptors: a versatile signaling module in organogenesis and oncogenesis. Neuron 18:847-855.

Campenot RB (1987) Local control of neurite sprouting in cultured sympathetic neurons by nerve growth factor. Brain Res 465:293-301.

Cartaud J, Changeux JP (1993) Post-transcriptional compartmentalization of acetylcholine receptor biosynthesis in the subneural domain of muscle and electrocyte junctions. Eur J Neurosci 5:191-202.

Cossu G, Tajbakhsh S, Buckingham M (1996) How is myogenesis initiated in the embryo? Trends Genet 12:218-223.

De La Porte S, Vigny M, Massoulié J, Koenig J (1984) Action of veratridine on acetylcholinesterase in cultures of rat muscle cells. Dev Biol 106:450-456.

Duclert A, Changeux JP (1995) Acetylcholine receptor gene expression at the developing neuromuscular junction. Physiol Rev 75:339-368.

Fallon JR, Hall ZW (1994) Agrin and dystroglycan: building synapses together. Trends Neurosci 17:469-473.

Fernandez-Valle C, Rotundo RL (1989) Regulation of acetylcholinesterase synthesis and assembly by muscle activity: effects of tetrodotoxin. J Biol Chem 264:14043-14049.

Grubic Z, Komel R, Walker WF, Miranda AF (1995) Myoblast fusion and innervation with rat motor nerve alter distribution of acetylcholinesterase and its mRNA in cultures of human muscle. Neuron 14:317-327.

Hall ZW, Ralston E (1989) Nuclear domains in muscle cells. Cell 59:771-772.

Hall ZW, Sanes JR (1993) Synaptic structure and development: the neuromuscular junction. Cell/Neuron Rev [Suppl] 72:99-121.
Horovitz O, Spitsberg V, Salpeter MM (1989) Regulation of acetylcholine receptor synthesis at the level of translation in rat primary muscle cells. J Cell Biol 108:1817-1822.

Jasmin BJ, Lee RK, Rotundo RL (1993) Compartmentalization of acetylcholinesterase mRNA and enzyme at the vertebrate neuromuscular junction. Neuron 11:467-477.

Johnson CD, Russell RL (1975) A rapid, simple radiometric assay for cholinesterase, suitable for multiple determinations. Anal Biochem 64:229-238.

Jones G, Moore CH, Hashemolhosseini S, Brenner HR (1999) Constitutively active MuSK is clustered in the absence of agrin and induces ectopic postsynaptic-like membranes in skeletal muscle fibers. J Neurosci 19:3376-3383.

Koenig J, Vigny M (1978) Neural induction of the $16 \mathrm{~S}$ acetylcholinesterase in muscle cell cultures. Nature 271:75-77.

Koenig J, Oren M, Malone MA (1982) Establishment of neuromuscular contacts in cultures of rat embryonic cells: effects of tetrodotoxin on maturation of muscle fibers and on formation and maintenance of acetylcholinesterase and acetylcholine receptor clusters. Dev Neurosci 5:314-325.

Legay C, Huchet M, Massoulié J, Changeux JP (1995) Developmental regulation of acetylcholinesterase transcripts in the mouse diaphragm: alternative splicing and focalization. Eur J Neurosci 7:1803-1809.

Massoulié J, Pezzementi L, Bon S, Krejci E, Vallette FM (1993) Molecular and cellular biology of cholinesterases. Prog Neurobiol 41:31-91.

Michel RN, Vu CQ, Tetzlaff W, Jasmin BJ (1994) Neural regulation of acetylcholinesterase mRNAs at mammalian neuromuscular synapses. J Cell Biol 127:1061-1069.

Molkentin JD, Olson EN (1996) Combinatorial control of muscle development by basic helix-loop-helix and MADS-box transcription factors. Proc Natl Acad Sci USA 93:9366-9373.

Peng HB, Xie H, Rossi SG, Rotundo RL (1999) Acetylcholinesterase clustering at the neuromuscular junction involves perlecan and dystroglycan. J Cell Biol 145:911-921.

Rieger F, Koenig J, Vigny M (1980) Spontaneous contractile activity and the presence of the $16 \mathrm{~S}$ form of acetylcholinesterase in rat muscle cells in culture. Dev Biol 76:358-365.

Rossi SG, Rotundo RL (1992) Cell surface acetylcholinesterase molecules on multinucleated myotubes are clustered over the nucleus of origin. J Cell Biol 119:1657-1667.

Rossi SG, Rotundo RL (1993) Localization of "non-extractable" acetylcholinesterase to the vertebrate neuromuscular junction. J Biol Chem 268:19152-19159.

Rossi SG, Rotundo RL (1996) Transient interactions between collagentailed acetylcholinesterase and sulfated proteoglycans prior to immobilization on the extracellular matrix. J Biol Chem 271:1979-1987.

Rotundo RL (1984a) Purification and properties of the membranebound form of acetylcholinesterase from chicken brain. Evidence for two distinct polypeptide chains. J Biol Chem 259:13186-13194.

Rotundo RL (1984b) Asymmetric acetylcholinesterase is assembled in the Golgi apparatus. Proc Natl Acad Sci USA 81:479-483.

Rotundo RL (1990) Nucleus-specific translation and assembly of acetylcholinesterase in multinucleated muscle cells. J Cell Biol 110:715-719.

Rotundo RL, Fambrough DM (1980) Synthesis, transport and fate of acetylcholinesterase in cultured chick embryo muscle cells. Cell 22:583-594.

Rotundo RL, Rossi SG, Anglister L (1997) Transplantation of quail collagen-tailed acetylcholinesterase molecules onto the frog neuromuscular synapse. J Cell Biol 136:367-374.

Rubin LL (1985) Increases in muscle $\mathrm{Ca}^{2+}$ mediate changes in acetylcholinesterase and acetylcholine receptors caused by muscle contraction. Proc Natl Acad Sci USA 82:7121-7125.

Rubin LL, Chalfin NA, Adamo A, Klymbowsky MW (1985) Cellular and secreted forms of acetylcholinesterase in mouse muscle cultures. J Neurochem 45:1932-1940.

Sambrook J, Fritsh EF, Maniatis T (1989) Molecular cloning: a laboratory manual. Cold Spring Harbor, NY: Cold Spring Harbor Laboratory.

Termin A, Pette D (1992) Changes in myosin heavy-chain isoform synthesis of chronically stimulated rat fast-twitch muscle. Eur J Biochem 204:569-573.

Tsim KWK, Greenberg I, Rimer M, Randall WR, Salpeter MM (1992) Transcripts for acetylcholine esterase show distribution differences in cultured chick muscle cells. J Cell Biol 118:1201-1212. 